\title{
MATRIKS PANGKAT DAN KEPERIODIKANNYA DALAM ALJABAR MAX-PLUS
}

The Power of Matrices and its Periodic in the Max-Plus Algebra

\author{
VENN YAN ISHAK ILWARU \\ Jurusan Matematika Fakultas MIPA Universitas Pattimura \\ Jl. Ir. M. Putuhena, Kampus Unpatti, Poka-Ambon \\ E-mail: vennilwaru007@gmail.com
}

\begin{abstract}
ABSTRAK
Dalam aljabar max-plus telah banyak dipelajari tentang sifat-sifat matriks.Salah satunya adalah keperiodikan suatu matriks yang tidak tereduksi. Telah diketahui pada aljabar maxplus bahwa barisan pangkat $A^{k}$ dalam Aljabar Max-Plus, dengan $A$ adalah matriks persegi yang tidak tereduksi, menjadiperiodiksetelahwaktuterbatas $T(A)$, danperiodeakhir $\gamma$ samadengan siklisitas grafkritis dari $A$. Dalamhubunganini dipelajari masalah komputasi dari matriks persegi yang berukuran $n \times n$ yaitu jika diberikan $k$, hitung periodik pangkat $A^{r}$ dengan $r=k(\bmod \gamma)$ untuk $r \geq T(A)$. Ide utama adalah menggunakan penskalaan similaritas diagonal yang sesuai $A \mapsto X^{-1} A X$, yang disebut penskalaan visualisasi.
\end{abstract}

Kata Kunci : Graf Kritis, Periodik Pangkat, Periodik akhir.

\section{PENDAHULUAN}

Pada Aljabar max-plus banyak permasalahan yang muncul, sehingga permasalahan itu dapat diselesaikan dengan mendapatkan suatu solusi yang tepat.Dalam penyelesaiannya, dibutuhkan analisis atau dengan menggunakan komputasi.Aljabar max-plus sering digunakan untuk memodelkan suatu permasalahan seperti transportasi, manufacturing, penjadwalan, sistem antrian, lalu lintas dan sebagainya.

Salah satu kegunaan dari pada aljabar max-plus yaitu dapat menyelesaikan dan mendapatkan suatu keperiodikan dari suatu permasalahan.Periodik yang dimaksud disini adalah periodik secara berkala.Untuk mempelajari periodik secara berkala, maka perlu dibahas visualisasi, dan perpangkatan matriks.Sehingga dapat membantu dalam menyelesaiakan dan mendapatkan suatu periodik secara berkala.

Pada penelitian ini akan dibahas mengenai permasalahan yang diberikan oleh Sergei Sergeev (2009) yaitu menghitung periodik pangkat $A^{r}$ dan mendapatkan perilaku periodik akhir dari $\left\{A^{l} \otimes x\right\}$.

\section{TINJAUAN PUSTAKA}

Pada penelitian-penelitian sebelumnya telah banyak dibahas mengenai matriks tidak tereduksi dan matriks boolean. Pada (Bart De Schutter dkk, 1998) telah diberikan mengenai definisi dari pada matriks tidak tereduksi dan matriks boolean. Pada (Martin Cavalec,1999) juga telah diberikan definisi mengenai keperiodikan suatu matriks.

Berikut ini akan diberikan materi yang diperlukan dalam pengerjaan penelitian. Materi yang diperlukan yaitu aljabar max-plus, vektor dan matriks pada aljabar max-plus, masalah spektral pada aljabar max-plus dan teori Kleene star.

Didefinisikan $\quad \stackrel{d e f}{=}-\infty$ dan $\quad \stackrel{d e f}{=} 0$. Himpunan $R_{\max }$ adalah himpunan $\mathfrak{R} \cup\{\varepsilon\}$, dimana $\mathfrak{R}$ adalah himpunan bilangan riil.

\section{Definisi 1}

Simbol $R_{\max }$ menyatakan himpunan $\mathfrak{R} \cup\{\varepsilon\}$ dengan dua operasi biner yaitu maksimum yang dinotasikan $\oplus$ dan penjumlahan yang dinotasikan $\otimes$. 
Untuk setiap $a, b \in R_{\max }$, didefinikan operasi $\oplus$ dan $\otimes$ adalah

$$
a \oplus b \stackrel{\text { def }}{=} \operatorname{maks}(a, b) \text { dan } a \otimes b=a+b .
$$

Sehingga untuk setiap $a \in R_{\text {max }}$ dan $\varepsilon$ didapatkan $a \oplus \varepsilon=\varepsilon \oplus a=a$ dan $a \otimes \varepsilon=\varepsilon \otimes a=\varepsilon$.

Himpunan $R_{\max }$ dengan operasi $\oplus$ dan $\otimes$ disebut Aljabar Max-plus dan dinyatakan dengan $\mathfrak{R}=\left(R_{\max }, \oplus, \otimes, \varepsilon, e\right)$.

Berikut adalah sifat-sifat Aljabar Max-plus (Heidergott dkk, 2006) sebagai berikut:

a. Asosiatif

$$
\begin{aligned}
& \forall x, y, z \in R_{\text {max }}: x \oplus(y \oplus z)=(x \oplus y) \oplus z, \\
& \text { dan } \\
& \forall x, y, z \in R_{\text {max }}: x \otimes(y \otimes z)=(x \otimes y) \otimes z
\end{aligned}
$$

b. Komutatif

$$
\forall x, y \in R_{\max }: x \oplus y=y \oplus x
$$

dan

$$
x \otimes y=y \otimes x
$$

c. Distributif $\otimes$ terhadap $\oplus$

$$
\forall x, y, z \in R_{\text {max }}: x \otimes(y \oplus z)=(x \otimes y) \oplus(x \otimes z)
$$

d. Eksistensi elemen nol, yaitu $\varepsilon$

$$
\forall x \in R_{\text {max }}: x \oplus \varepsilon=\varepsilon \oplus x=x
$$

e. Eksistensi elemen satuan, yaitu $e$

$$
\forall x \in R_{\max }: x \otimes e=e \otimes x=x
$$

f. Elemen nol adalah absorbing untuk operasi $\otimes$

$$
\forall x \in R_{\max }: x \otimes \varepsilon=\varepsilon \otimes x=\varepsilon
$$

g. $\quad$ Idempoten dari operasi $\oplus$

$$
\forall x \in R_{\max }: x \oplus x=x
$$

\section{Lemma 1}

Misalkan $A \in R_{\max }^{n \times n}$ mempunyai nilai eigen $\lambda$ yang berhingga, maka ada sebuah sirkuit $p$ di $G(A)$ sehingga

$$
\lambda=\frac{|p|_{w}}{|p|_{l}}
$$

\section{Teorema 1}

Sebarang matriks tidak tereduksi $A=R_{\max }^{n \times n}$ mempunyai satu dan hanya satu nilai eigen $\lambda$. Nilai eigen $\lambda$ ini adalah bilangan berhingga dan nilainya sama dengan bobot rata-rata maksimum dari sirkuit pada $G(A)$ yaitu:

$$
\lambda(A)=\max _{p \in C(A)} \frac{|p|_{w}}{|p|_{l}} .
$$

\section{Teorema 2}

Misalkan sistem $x(k+1)=A \otimes x(k)$ memenuhi asumsi dasar bahwa sistem mempunyai nilai eigen yang tunggal dan jika diberikan nilai awal $x(0) \neq \varepsilon$, sistem akan bersifat periodik setelah iterasi yang berhingga. Misalkan $p, q$ adalah bilangan bulat dengan $p>q \geq 0$ dan $c$ adalah bilangan riil yang berhingga sehingga $x(p)=x(q) \otimes c$. Maka nilai eigen dari sistem adalah $\lambda=\frac{c}{p-q}$ dengan vektor eigen yang bersesuaian adalah $v=\oplus_{j=1}^{p-q}\left(\lambda^{\otimes(p-q-j)} \otimes x(q+j-1)\right)$.

Dari teorema di atas, didapatkan Algoritma Power untuk menentukan nilai eigen dan vektor eigen.

\section{Algoritma Power (Subiono, 2000, hal. 86)}

1) Ambil sebarang vektor awal $x(0)=x_{0} \neq \mathbf{u}[\varepsilon]$, yaitu $x_{0}$ mempunyai minimal satu elemen berhingga.

2) Iterasi $x(k+1)=A \otimes x(k)$ hingga ada bilangan bulat $p, q$ dengan $p>q \geq 0$ dan sebuah bilangan riil csehingga $x(p)=x(q) \otimes c$, hingga suatu periodik didapatkan.

3) Hitung nilai eigen $\lambda=\frac{c}{p-q}$.

4) Hitung vektor eigen

$$
v=\bigoplus_{j=1}^{p-q}\left(\lambda^{\otimes(p-q-j)} \otimes x(q+j-1)\right) .
$$

Untuk setiap $A \in R_{+}^{n \times n}$

$A$ adalah Kleene star $\Leftrightarrow A^{2}=A, a_{i i}=1, \forall i$ $\Leftrightarrow a_{i j} a_{j k} \leq a_{i k}, a_{i i}=1, \forall i, j, k$

Kondisi $\lambda(A) \leq 1$ menunjukan bahwa ada hubungan yang kuat antara kleene stars dan masalah spektral.

\section{Proposisi 1}

Diberikan $A \in R_{\max }^{n \times n}$ terdefinisi dan $X=\operatorname{diag}(x)$

1) Jika $x=\bigoplus_{i=1}^{n} A_{. i}^{*}$ maka $X^{-1} A X$ adalah visualisasi

2) Jika $\quad x=\sum_{i=1}^{n} A_{. i}^{*} \quad$ maka $\quad X^{-1} A X \quad$ adalah visualisasistrictly.

\section{Proposisi 2}

Diberikan $A \in R_{\max }^{n \times n}$ terdefinisi dan diberikan $t \geq 0$ sedemikian sehingga $t_{\gamma} \geq n^{2}$. Diberikan $i, j \leq c$ sedemikian sehingga $[i] \rightarrow_{l}[j], l \leq \gamma$, mengakibatkan $[j] \rightarrow_{s}[i]$, dimana $l+s=\gamma$.

1) Jika $A$ divisualisasikan maka $a_{i j}^{(t \gamma+l)}=a_{j i}^{(t \gamma+s)}=1$

2) Pada kasus umum $a_{i j}^{(t \gamma+l)} a_{j i}^{(t \gamma+s)}=1$ 


\section{HASIL DAN PEMBAHASAN}

\section{Proyektor Spektral dan Matriks Periodesitas}

Untuk matriks $A \in R_{\max }^{n \times n}$ yang tidak tereduksi dan terdefinisi, sesuai dengan matriks $Q(A)$ dengan elemenelemen:

$$
q_{i j}=\bigoplus_{k=1}^{c} a_{i k}^{*} a_{k j}^{*}, \quad i, j=1, \ldots, n_{c}
$$

Operator max-plus linear matriks $Q(A)$ adalah proyektor spektral max-plus linear yang berkaitan dengan $A$, dalam arti bahwa $R_{\max }^{n}$ pada eigencone $V(A)$. Operator ini sangat berkaitan dengan masalah periodisitas. $Q(A)$ disebut juga matriks orbital.

\section{Definisi 2.}

Diberikan matriks $A \in R_{\max }^{n \times n}, Q \in R_{\max }^{n \times n}$ yang memenuhi $A Q=Q A=Q^{2}$ disebut spektral proyektor dari $A$ yang berhubungan dengan nilai eigen $\lambda$.

Jika diberikan $A \in R_{\max }^{n \times n}$ yang tidak tereduksi dan terdefinisi dan diberikan $C(A)$ adalah primitive, maka terdapat bilangan bulat $T(A)$ sehingga $A^{r}=Q(A)$, untuk semua $r \geq T(A)$.

Untuk matriks $A \in R_{\max }^{n \times n}$ yang tidak tereduksi dan terdefinisi, setiap kolom kritis (atau baris) dari $Q(A)$ adalah sama dengan korenspondensi kolom (atau baris) dari $A^{*}$. Ketika $C(A)$ mempunyai komponen imprimitive, sesuai dengan proposisi bahwa semua komponen dari $C\left(A^{\gamma}\right)$ adalah primitive, dimana $\gamma$ adalah siklisitas dari $C(A)$. Oleh karena itu, untuk setiap $r$ yang cukup besar adalah kelipatan dari $\gamma, A^{r}$ adalah matriks dari proyektor spektral dalam eigencone dari $A^{\gamma}$. Ini juga mengakibatkan bahwa untuk $r$ yang cukup besar, mempunyai $A^{r}=A^{r+\gamma}$. Jumlah $r$ setelah dimulai disebut transient dari $\left\{A^{r}\right\}$ dan dinotasikan dengan $T(A)$. Juga diketahui bahwa $\gamma$ adalah periode akhir dari $\left\{A^{r}\right\}$ yakni sedikitnya bilangan bulat $\alpha$ sehingga $A^{r+\alpha}=A^{r}$ untuk semua $r \geq T(A)$. Elemen $a_{i j}^{(r)}$, dimana $i$ atau $j$ adalah kritis, menjadi periodik jauh lebih cepat dari bagian non kritis dari $A$.

Berikut ini adalah proposisi untuk menentukan keperiodikan baris kritis dan kolom kritis dari matriks $A^{r}$

(a)

\section{Proposisi 3.}

Diberikan $A \in R_{\max }^{n \times n}$ yang tidak tereduksi dan terdefinisi. Baris dan kolom kritis dari $A^{r}$ menjadi periodik untuk $r \geq n^{2}$.

\section{Bukti}

Diberikan $i \leq c$, maka terdapat sirkuit kritis dari panjang $l_{i}$. Oleh karena itu $a_{i i}^{\left(k l_{i}\right)}=1$ untuk $k \geq 1$. Untuk semua $m<k$ dan beberapa $t=1, \ldots, n$, maka diperoleh:

$a_{i s}^{\left(m l_{i}\right)}=a_{i i}^{\left((k-m) l_{i}\right)} a_{i s}^{\left(m l_{i}\right)} \leq a_{i s}^{\left(k l_{i}\right)}$

Selanjutnya

$$
a_{i s}^{\left(k l_{i}\right)}=\bigoplus_{m=1}^{k} a_{i s}^{\left(m l_{i}\right)} .
$$

Elemen-elemen $a_{i s}^{\left(k l_{i}\right)}$ merupakan bobot maksimal dari path dengan panjang $k$ yang bersesuaian dengan matriks $A^{l_{i}}$. Karena bobot dari semua sirkuit adalah kurang dari atau sama dengan 1 dan semua path dari panjang $n$ tidak sederhana. Maksimum dicapai pada saat $k \leq n$. Maka diperoleh bahwa $a_{i s}^{\left((t+1) l_{i}\right)}=a_{i s}^{\left(t l_{i}\right)}$ untuk semua $t \geq n$. Lebih lanjut

$$
a_{i s}^{\left((t+1) l_{i}+d\right)}=\bigoplus_{p} a_{i p}^{\left(t l_{i}\right)} a_{p s}^{(d)}
$$

Selanjutnya $a_{i s}^{\left((t+1) l_{i}+d\right)}=a_{i s}^{\left(t l_{i}+d\right)}$ untuk semua $t \geq n$ dan $0 \leq d \leq l_{i}-1$. Sehingga $a_{i s}^{(k)}$ periodik untuk $k \geq n l_{i}$ dan semua urutannya untuk setiap $i \leq c$ dan setiap $s$, menjadi periodik untuk $k \geq n^{2}$

\section{Sifat-sifat Periodik Perpangkatan Matriks}

Periodik pangkat dari matriks yang tidak tereduksi dan terdefinisi dijelaskan dengan proposisi-proposisi berikut.

\section{Proposisi 4.}

Diberikan matriks $A \in R_{\max }^{n \times n}$ yang tidak tereduksi dan terdefinisi dan $t \geq 0$ sehingga $t \gamma \geq T(A)$. Maka untuk setiap bilangan bulat $l \geq 0$

$$
\begin{aligned}
& a_{k .}^{(t \gamma+l)}=\bigoplus_{i=1}^{c} a_{k i}^{(t \gamma)} A_{i .}^{(t \gamma+l)}, a_{. k}^{(t \gamma+l)}=\bigoplus_{i=1}^{c} a_{i k}^{(t \gamma)} A_{. i}^{(t \gamma+l)}, \\
& 1 \leq k \leq n
\end{aligned}
$$

\section{Bukti}

Untuk $B=A^{\gamma}$ dan setiap $t \geq T(B)$ diperoleh

$$
b_{k j}^{(r)}=\bigoplus_{i=1}^{c} b_{k i}^{*} b_{i j}^{*}, \quad 1 \leq k, j \leq n
$$

Dengan demikian diperoleh

$b_{k i}^{*}=b_{k i}^{(t)}=a_{k i}^{(t \gamma)}$

dan

$b_{i j}^{*}=b_{i j}^{(t)}=a_{i j}^{(t \gamma)}$ 
untuk semua $t \geq T(B)$ atau ekuivalen dengan $t \gamma \geq T(A)$ dan setiap $i \leq c$. Oleh karena itu

$a_{k j}^{(t \gamma)}=\bigoplus_{i=1}^{c} a_{k i}^{(t \gamma)} a_{i j}^{(t \gamma)}, \quad 1 \leq k, j \leq n$

Pada notasi matriks, persamaan di atas ekuivalen dengan $A_{k .}^{t \gamma}=\bigoplus_{i=1}^{c} a_{k i}^{(t \gamma)} A_{i .}^{t \gamma}, \quad A_{. k}^{t \gamma}=\bigoplus_{i=1}^{c} a_{i k}^{(t \gamma)} A_{. i}^{t \gamma}, 1 \leq k \leq n$

Perkalian persamaan (6) dengan matriks pangkat $A^{l}$ akan diperoleh persamaan (3)

Pada pembuktian proposisi berikut akan digunakan prinsip sederhana berikut ini:

$a_{i j}^{(r)} a_{j k}^{(s)} \leq a_{i k}^{(r+s)}, \forall i, j, k, r, s$

\section{Proposisi 5.}

Diberikan matriks $A \in R_{\max }^{n \times n}$ yang tidak tereduksi dan terdefinisisi dan diberikan $i, j \in N_{c}(A)$ sedemikian sehingga $[i] \rightarrow_{l}[j]$, untuk $0 \leq 1<\gamma$.

1) Terdapat $t$ sedemikian sehingga untuk setiap $r \geq n^{2}$

$$
a_{i j}^{(t \gamma+l)} A_{. i}^{r}=A_{. j}^{r+l}, a_{i j}^{(t \gamma+l)} A_{j .}^{r}=A_{i .}^{r+l}
$$

2) Jika matriks $A$ adalah visualisasi maka untuk semua $r \geq n^{2}$

$$
A_{. i}^{r}=A_{. j}^{r+l}, A_{j .}^{r}=A_{i .}^{r+l}
$$

\section{Bukti}

Diberikan $s=\gamma-l$. Dengan proposisi 2, terdapat $t$ sedemikian sehingga $a_{i j}^{(t \gamma+l)} a_{j i}^{(t \gamma+s)}=1$. Jika digabungkan dengan persamaan (7) maka diperoleh

$$
\begin{aligned}
& A_{. i}^{r}=A_{. i}^{r} a_{i j}^{(t \gamma+l)} a_{j i}^{(t \gamma+s)} \leq A_{. j}^{r+t \gamma+l} a_{j i}^{(t \gamma+s)} \leq A_{. i}^{r+(2 t+1) \gamma} \\
& A_{j .}^{r}=A_{j .}^{r} a_{i j}^{(t \gamma+l)} a_{j i}^{(t \gamma+s)} \leq A_{i .}^{r+t \gamma+l} a_{j i}^{(t \gamma+s)} \leq A_{j .}^{r+(2 t+1) \gamma}
\end{aligned}
$$

Dengan proposisi $2, A_{. i}^{r}=A_{. j}^{r+t \gamma}$ dan $A_{j .}^{r}=A_{i .}^{r+t \gamma}$ untuk semua $t \geq 0$ dan $r \geq n^{2}$ maka semua ketidaksamaan pada persamaan (8) menjadi persamaan. Perkaliannya dengan $a_{i j}^{(t \gamma+l)}$ diperoleh persamaan

$$
A_{. i}^{r}=A_{. j}^{r+l}, A_{j .}^{r}=A_{i .}^{r+l}
$$

Diambil $t \gamma \geq T(A)$. Untuk setiap $l \geq 0$, diberikan $C^{(l)} \in R_{\max }^{n \times c} \quad$ atau sebaliknya $R^{(l)} \in R_{\max }^{n \times c} \quad$ menjadi matriks yang diekstrak dari klom kritis dari $A^{t \gamma+l}$ atau sebaliknya dari baris kritis $A^{t \gamma+l}$. Diberikan $C:=C^{(0)}, R:=R^{(0)}$. Dengan notasi ini dan dari proposisi 4 dan proposisi 5, maka dapat disimpulkan bahwa untuk visualisasi matriks tidak tereduksi $A \in R_{\max }^{n \times n}$
$A^{t \gamma+l}=C^{(l)} \otimes R=C \otimes R^{(l)}$

$C^{(l)}=C \otimes\left(A^{[C]}\right)^{l}, R^{(l)}=\left(A^{[C]}\right)^{l} \otimes R$

Persamaan (11) setara dengan persamaan (3). Lebih lanjut $[i] \rightarrow_{l}[j]$ jika dan hanya jika terdapat indeks $p \in[i]$ dan $s \in[j]$ sedemikian sehingga elemen $(p, s)$ dari $\left(A^{[C]}\right)^{l}$ adalah 1 , dan semua baris dari $R$ atau kolom dari $C$, dengan indeks yang sama dengan kelas siklik adalah sama satu sama lain .

Dengan menggabungkan persamaan (11) dan persamaan (12) maka diperoleh

$$
A^{t \gamma+l}=C \otimes\left(A^{[C]}\right)^{l} \otimes R
$$

Jika $A$ tidak tervisualisasi tetapi terdefinisi tidak tereduksi, maka persamaan (12) dan persamaan (13) dapat dituliskan. Diberikan $B=X^{-1} A X$ tervisualisasi. Dengan menerapkan penskalaan invers $X B X^{-1}$ pada persamaan (13) (dimana $B$ digantikan dengan $A$ ) maka diperoleh persamaan dari bentuk yang sama, dimana $C$ dan $R$ adalah matriks yang diekstrak dari kolom kritis atau sebaliknya baris dari $A^{t \gamma}$ dan $A^{[C]}$ digantikan dengan matriks $A^{[C]}=\left(a_{i j}^{(C)}\right) \in R_{\max }^{c \times c}$ yang didefinisikan dengan

$$
a_{i j}^{(C)}= \begin{cases}a_{i j}, & \text { jika }(i, j) \in E_{c}(A), \quad i, j \leq c \\ 0 & \text { jika }(i, j) \notin E_{c}(A),\end{cases}
$$

\section{Penyelesaian Masalah Keperiodikan}

Diberikan $A \in R_{\max }^{n \times n}$ dan $\lambda(A)=1 . \quad$ tattraction cone $\operatorname{Attr}(A, t)$ adalah maxcone yang terdiri dari semua vektor $x$, dimana terdapat bilangan bulat $r$ sehingga $A^{r} \otimes x=A^{r+t} \otimes x$ dan hal ini juga berlaku untuk semua bilangan bulat yang lebih besar atau sama dengan $r$.

\section{Proposisi 6}

Diberikan matriks $A$ tidak tereduksi dan terdefinisi. Sistem $A^{r} \otimes x=A^{r+t} \otimes x \quad$ setara dengan semua $r \geq T(A)$.

\section{Bukti}

Diberikan $x$ yang memenuhi $A^{s} \otimes x=A^{s+t} \otimes x$ untuk $s \geq T(A)$, maka juga akan memenuhi sistem ini untuk semua yang lebih besar dari s. Karena periodisitas untuk semua $k$ dari $T(A) \leq k \leq s$ terdapat $l>s$ sehingga

$$
A^{k}=A^{l} . A^{k} \otimes x=A^{k+t} \otimes x
$$

juga memenuhi $T(A) \leq k \leq s$

\section{Akibat 1.}

$\operatorname{Attr}(A, t)=\operatorname{Attr}\left(A^{t}, 1\right)$ 


\section{Bukti}

Dengan proposisi 5, $\operatorname{Attr}(A, t)$ adalah solusi untuk sistem $A^{r} \otimes x=A^{r+t} \otimes x$ untuk setiap $r \geq T(A)$ yang adalah kelipatan dari $t$

Komponen dari $A^{r} \otimes x=A^{r+t} \otimes x$ dengan indeks pada $N_{c}(A)=\{1, \ldots, c\}$ disebut kritis dan subsistem dari komponen-komponen dengan indeks ini disebut subsistem kritis.

\section{Lemma 2.}

Diberikan matriks $A$ tidak tereduksi dan terdefinisi dan diberikan $r \geq T(A)$. Maka $A^{r} \otimes x=A^{r+t} \otimes x$ setara dengan subsistem kritis.

\section{Bukti}

Berdasarkan komponen non kritis $A_{k .}^{r} \otimes x=A_{k}^{r+t} \otimes x$. Dengan menggunakan persamaan (3) maka dapat dituliskan:

$$
\bigoplus_{i=1}^{c} a_{k i}^{(r)} A_{i .}^{r} \otimes x=\bigoplus_{i=1}^{c} a_{k i}^{(r)} A_{i .}^{r+t} \otimes x
$$

Hal ini merupakan kombinasi maksimum dari persamaan pada subsistem kritis

Berikutnya diberikan batasan dalam menghitung kompleksitas dalam memutuskan apakah $x \in \operatorname{Attr}(A, t)$, seperti masalah-masalah yang lain yang dapat diformulasikan seperti di bawah ini:

P1. Diberikan $x$, uji apakah $x \in \operatorname{Attr}(A, t)$

P2. Diberikan $x$ : $0 \leq k<\gamma$, hitung periodik matriks pangkat $A^{r}$ dimana $r=k(\bmod \gamma)$.

P3. Diberikan $x$, hitung periodik akhir dari $\left\{A^{r} \otimes x, r \geq 0\right\}$, yang berarti sedikitnya bilangan bulat $\gamma$ sedemikian sehingga $A^{r+\gamma} \otimes x=A^{r} \otimes x$ untuk semua $r \geq T(A)$.

Untuk menyelesaikan P1-P3, maka dapat menggunakan metode sebagai berikut:

Pertama-tama perhatikan bahwa $\lambda(A)$ dan vektor subeigen dapat dihitung dan mengidentifikasi semua titik kritis yang dilakukan dengan algoritma FloydWarshall.Selanjutnya mengidentifikasi semua kelas siklik $C(A)$ dengan kondensasi Balcer-Veinott. Dengan proposisi 4, kolom kritis dan baris kritis menjadi periodik untuk $r \geq n^{2}$. Dengan mengetahui kolom kritis dan baris kritis pada $r^{\prime} \geq T(A)$, itu sudah cukup untuk menghitung $A^{r}$ untuk $r \geq n^{2}$, yang dapat diselesaikan dengan perpangkatan matriks persegi $\left(A, A^{2}, A^{4}, \ldots\right)$. Persamaan (9) digunakan untuk permutasi siklik yang sesuai dengan kelas siklik. P1 dapat diselesaikan dengan verifikasi dari subsistem kritis dari $A^{r^{\prime}} \otimes x=A^{r^{\prime}+t} \otimes x$. Dengan menggunakan bantuan persamaan (3), sisa submatriks non kritis dari $A^{r}$, untuk setiap $r \geq T(A)$ sehingga $r=k(\bmod \gamma)$ dapat dihitung. Ini adalah penyelesaian untuk P2. Baris non kritis dari matriks $A$ merupakan generalisasi dari baris kritis, periodik akhir dari $\left\{A^{r} \otimes x\right\}$ ditentukan dari komponen-konponen kritis. Untuk visualisasi matriks, diketahui bahwa $A_{i}^{r+t}=A_{j}^{r}$. untuk semua $i, j$ sehingga $[i] \rightarrow_{t}[j]$. Ini berarti $\left(A^{r} \otimes x\right)_{i}=\left(A^{r+t} \otimes x\right)_{j}$ untuk $[i] \rightarrow_{t}[j]$, artinya bahwa untuk menentukan periode dibutuhkan hanya sub vektor dari $A^{r} \otimes x$ untuk setiap sembarang $r \geq n^{2}$. Untuk $i \leq c$ dan $\quad r \geq n^{2}, \quad$ barisan $\quad\left\{\left(A^{r} \otimes x\right)_{i}, t \geq 0\right\} \quad$ dapat direpresentasikan dengan barisan dari koordinat kritis dari $A^{r} \otimes x$ yang ditentukan oleh suatu permutasi pada kelas siklik $\gamma_{\mu}$ dari komponen strongly connected. Untuk menghitung periode, dapat diambil contoh banyaknya $\gamma_{\mu}$ secara berurutan pada barisan dan periksa semua periodeperiode yang mungkin. Periode dari $A^{r} \otimes x$ akan tampak seperti l.c.m. pada periode ini. Ini adalah penyelesaian P3.

\section{KESIMPULAN}

Kesimpulan yang dapat diperoleh dari penelitian ini adalah sebagai berikut:

1) Jika diberikan matriks $A \in R_{\max }^{n \times n}$ yang tidak tereduksi dan tervisualisasi maka baris kritis dan kolom kritis akan menjadi periodik utuk $r \geq n^{2}$.

2) Keperiodikan dari perpangkatan matriks persegi $A^{r}$, dapat dihitung untuk $r \geq T(A)$ dan jika $k$ diketahui.

\section{DAFTAR PUSTAKA}

Bacelli, F., Cohen, G., Olsder, G. J., dan Quadrat, J. P. (2001), Synchronization and Linearity, John Wiley \& Sons, New York.

Papadimitriou, C. H., Steiglitz, K., Combinatorial Optimization: "Algorithms and Complexity", Prentice Hall, New Jersey, 1982

Heidergott, B. (2006), Max Plus Algebra And Queues, Vrije Universiteit. Department of Econometrics and Operations Research De Boolean 1105, 1081 HV Amsterdam, The Netherlands.

Gavalec, M., "Linear Matrix Period in Max-Plus Algebra”, Linear Algebra Appl. 307(2000) 167-182

Butkovic, P., Cuninghame-Green, R. A., "On matrix powers in max-algebra”, Linear Algebra Appl.

Subiono. (2009), Aljabar Max-Plus, Institut Teknologi Sepuluh Nopember, Surabaya 
Sergeev, S., Schneider, H., Butkovic, P. (2009) "On visualization scaling, subeigenvectors and kleene stars in max algebra”, Linear Algebra Appl. 